\title{
Mandibular vascular hamartoma in a cat
}

\section{J. Vet. Med. Sci.}

80(9): 1456-1458, 2018

doi: 10.1292/jvms.18-0148

Received: 16 March 2018

Accepted: 3 July 2018

Published online in J-STAGE:

13 July 2018

\section{Satoshi TAKAGI ${ }^{1) *}$, Yumiko KAGAWA ${ }^{2)}$, Kiwamu HANAZONO'), Shoko MURAKAMI ${ }^{1}$, Tatsuya DEGUCHI ${ }^{3)}$, Yusuke IZUMI ${ }^{1}$, Kenji HOSOYA ${ }^{3)}$, Sangho $\mathrm{KIM}^{3)}$ and Masahiro OKUMURA ${ }^{3)}$}

\author{
1)Hokkaido University Veterinary Teaching Hospital, Kita-19jo Nishi-10, Kita-ku, Sapporo, \\ Hokkaido 060-0819, Japan \\ ${ }^{2)}$ North Lab., 8-35 Hondori 2 Kita, Shiroishi-ku, Sapporo, Hokkaido 003-0027, Japan \\ ${ }^{3)}$ Department of Veterinary Sciences, Graduate School of Veterinary Medicine, Hokkaido University, Kita-18jo \\ Nishi-9, Kita-ku, Sapporo, Hokkaido 060-0818, Japan
}

ABSTRACT. A 10-year-old cat presented for evaluation with a 1-month history of salivation and oral bleeding. A right mandibular mass was palpated and computed tomography examination revealed entire bone proliferation. Mandibular bone biopsy was performed, and histopathological diagnosis was vascular hamartoma. The cat suddenly died on day 140.

KEY WORDS: cat, hamartoma, mandibular

A hamartoma is a benign disease that is defined as an excessive and disordered growth of mature cells and tissues that are normally present in the area in which the lesion exists [12]. Consequently, a vascular hamartoma is a disorganized overgrowth of mature vascular cells; these cells construct abnormal blood vessels and form a tumor-like mass [13]. In dogs, hamartoma is a rare disease; cases of hamartoma in dogs have been sporadically reported $[1,7,16]$. However, case reports are limited regarding this disease in cats. Previously, hamartoma in the lung [3], kidney [5], nasal cavity [2], gingiva [10], and central nervous system [9, 11] of cats has been reported; the clinical outcome of those cases was excellent. In this report, we describe a cat that presented with a feline hamartoma of mandibular origin and eventually died due to the disease.

A 10 -year-old, 3.38-kg, neutered, male domestic shorthair cat was referred to the veterinary teaching hospital for evaluation regarding a 1-month history of intermittent salivation and slight bleeding from the oral cavity. On physical examination, a right mandibular swelling was detected. Additionally, gingival swelling, ulceration, and persistent lacrimation from the right eye was observed (Fig. 1). No difficulty or pain was observed when opening the mouth widely. The owner reported that the cat seemed to exhibit a strange sensation while eating food, although the cat's appetite and activity were normal.

Under general anesthesia, a computed tomography (CT) examination was performed. Severe bone proliferation, accompanied by bone resorption, was observed in the entire right mandibular bone, with intense contrast medium enhancement around the bone (Fig. 2). Soft tissue near the orbital bone was swollen. No abnormality was confirmed at the lymph node and lung. After CT evaluation, a biopsy, including deep soft tissue, was performed. This tissue contained abundant fibroblasts and abnormal irregular small vessels, which exhibited well-differentiated cells. A hamartoma was suspected, however there were insufficient histopathological characteristics for a definitive diagnosis.

On day 14, bone biopsy, via rongeur after tooth extraction, was attempted, in order to obtain the definitive diagnosis. During the procedure, severe bleeding was recognized with manipulation. On histopathological examination of the piece of mandibular bone, abundant blood vessels were observed, which comprised well-differentiated cells; the cat was diagnosed with vascular hamartoma (Fig. 3). Extraction of the right mandibula was recommended, but the owner declined surgical treatment. On day 126, the cat came to the veterinary teaching hospital because of severe bleeding from the oral cavity. The cat exhibited anorexia at that time, but recovered. The size of the right mandibular mass had increased; mild regenerative anemia (packed cell volume: $30 \%$ ) and difficulty in mouth-opening were observed. The cat was scheduled for mandibulectomy on day 140 , but died suddenly on the way to the hospital. From postmortem examination, the cause of death was suspected as hypotension due to severe bleeding with/without coagulation disfunction, or suffocation due to aspiration of the blood.

A hamartoma is defined as benign congenital disease manifesting as a mass composed of disorganized cells or tissues indigenous to the site; it grossly resembles neoplasia [9]. In human medicine, hamartoma has recently been regarded as neoplastic because it exhibits chromosomal aberrations that are acquired thorough somatic mutations [8]. This disease has been reported in many species, including humans [12], cattle [17, 18], dogs [1, 16], and cats [4, 13]. Few case reports of hamartomas in cats are available within the veterinary literature; the development of feline hamartoma is regarded as relatively uncommon, compared with other

*Correspondence to: Takagi, S.: staka@vetmed.hokudai.ac.jp

(c2018 The Japanese Society of Veterinary Science

This is an open-access article distributed under the terms of the Creative Commons Attribution Non-Commercial No Derivatives (by-nc-nd) License. (CC-BY-NC-ND 4.0: https://creativecommons.org/licenses/by-nc-nd/4.0/) 


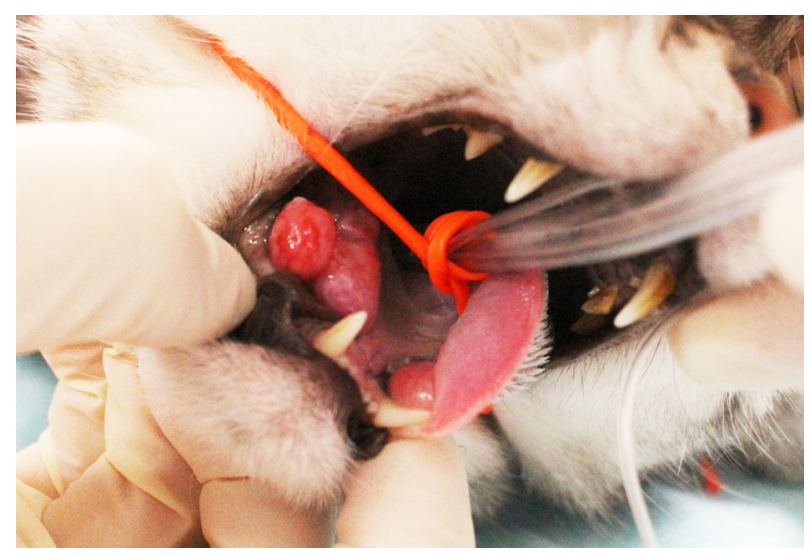

Fig. 1. Gross appearance of the mass. The right mandibular mass was confirmed at the rostral oral mucosa.
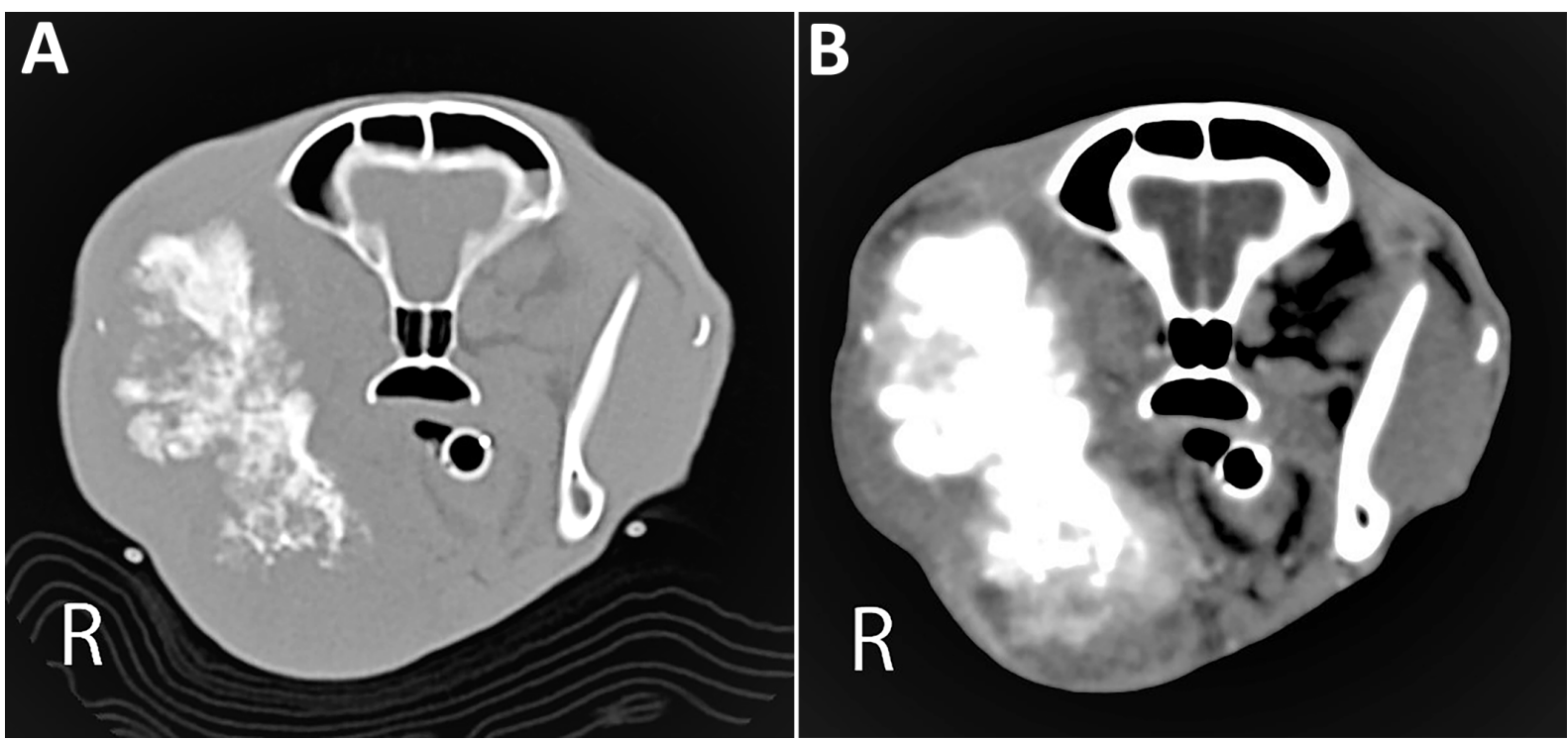

Fig. 2. Computed tomography findings at (A) bone window and (B) soft tissue window with contrast media. (A) The entire right mandibular bone was involved. (B) The soft tissue around the right mandibular bone was enhanced by the contrast media.
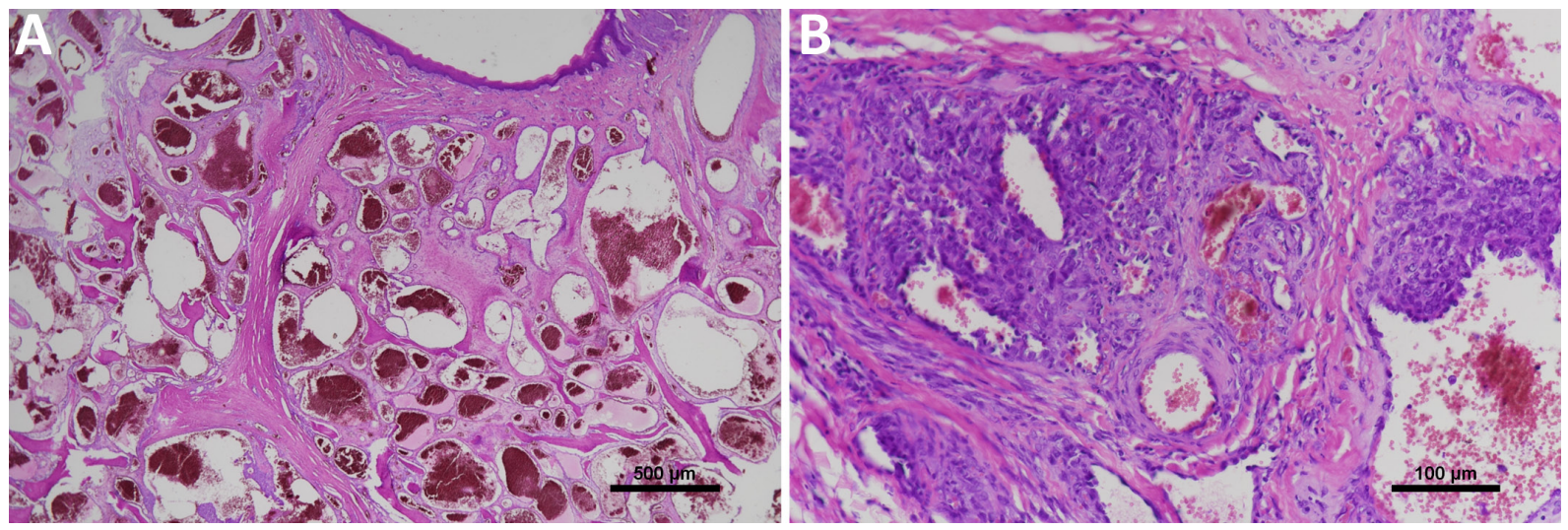

Fig. 3. Histopathological views of the mandibular tissue. Low-power (A) and high-power field (B). Bone tissue was replaced by irregular vascular and stromal proliferation. Endothelial cells of each vessel were well-differentiated without malignant findings. On the basis of these findings, this mandibular mass was diagnosed as vascular hamartoma. 
spices. Regarding primary oral hamartoma, there is one case report of a cat that developed hamartoma within the maxillary gingiva [10]. In that report, the lesion mainly existed at the gingiva; lysis of the alveolar bone around the right mandibular canine teeth (404) was confirmed by radiography. In contrast, in the present case, the lesion existed mainly at the mandibular bone, and was clearly observed by CT imaging. Histopathological examination also supported these findings; thus, the present case was diagnosed as a vascular hamartoma of mandibular origin, which has not been reported in the cat. In general, it is difficult to distinguish between hemangioma and hamartoma. In this case, immunohistochemistry staining for smooth muscle cells was performed (data not shown); variable, disorganized, mature vessels with smooth muscles were identified around the wall. These vessels were lined by well-differentiated endothelium and the vessel walls were thicker than typically observed in hemangioma.

Upon initial referral, the cat was suspected of squamous cell carcinoma of severe bone proliferation, which has been reported to exhibit better prognosis $[6,14]$. From the authors' experience, these types of mandibular lesions are difficult to definitively diagnose without bone biopsy [14]. In skeletal hamartoma, as in squamous cell carcinoma with reactive bone proliferation, a bone biopsy is required, but for different reasons. Hamartoma cannot be identified by fine needle aspiration or soft tissue biopsy, as this disease is typically composed of normal cells. Hence, bone biopsy was necessary. Transfusion was also considered for this examination.

In this cat, almost the entire right mandibular segment was replaced by the lesion. This disease is suspected of exhibiting a very slow growth rate, such that it may take a relatively long time to enlarge to the point of clinical relevance. From previous reports, the age of the diagnosis may depend on the location of the lesion. If the lesion causes clinical signs, it might be diagnosed at early stages of life: for example, at 3 years old for nasal lesions [2], 15 months old for spinal lesions [11], 8 months or 1 year old (two separate cases) for skin lesions [4], and 9 months old for vertebral lesions [15]. In contrast, gastric [13] and cerebral [9] hamartomas are both typically diagnosed at 11 years old; in these locations, the size may increase gradually without exhibiting any clinical signs and be difficult to discern merely by appearance, resulting in a delayed diagnosis, as in the present case.

A hamartoma is a benign lesion; thus, surgical extraction generated a good outcome in previous reports [10, 17]. Unfortunately, in this case, timely surgical intervention could not be performed; however, we anticipated prolonged survival if we were able to perform mandibulectomy. Surgery may be a good treatment for preventing severe bleeding, as well as enlargement of the mass and trismus.

\section{REFERENCES}

1. Bongiovanni, L., Suter, M. M., Malatesta, D., Ordinelli, A., Ciccarelli, A., Romanucci, M., Brenner, O. and Della Salda, L. 2012. Nuclear survivin expression as a potentially useful tool for the diagnosis of canine cutaneous sebaceous lesions. Vet. Dermatol. 23: 394-e73. [Medline] [CrossRef]

2. Chambers, B. A., Laksito, M. A., Fliegner, R. A., McCowan, C., Beck, C. and Yates, G. D. 2010. Nasal vascular hamartoma in a Domestic Shorthair cat. Aust. Vet. J. 88: 107-111. [Medline] [CrossRef]

3. Drolet, R. and Phaneuf, J. B. 1983. Pulmonary chondromatous hamartoma in a young cat. Vet. Rec. 113: 541-542. [Medline]

4. Heimann, M. H. and Ngendahayo, P. 2007. Sweat gland hamartoma resembling human syringocystadenoma papilliferum in two young cats. Vet. Dermatol. 18: 451-455. [Medline] [CrossRef]

5. Hodgin, E. C. 1985. Meningeal hemangioma and renal hamartoma in a heifer. Vet. Pathol. 22: 420-421. [Medline] [CrossRef]

6. Kosovsky, J. K., Mattheisen, S. M., Patnaik, A. K., Burk, R. L. and Matus, R. E. 1991. Mandibular swellings in cats: prospective study of 24 cats. $J$. Am. Hosp. Assoc. 27: 575-580.

7. Kuhlman, G. M., Taylor, A. R., Thieman-Mankin, K. M., Griffin, J., Cook, A. K. and Levine, J. M. 2016. Use of a frameless computed tomographyguided stereotactic biopsy system for nasal biopsy in five dogs. J. Am. Vet. Med. Assoc. 248: 929-934. [Medline] [CrossRef]

8. Kumar, V., Abbas, A. K. and Aster, J. C. 2018. Neoplasia. pp. 189-242. In: Basic Pathology. 10th ed. (Kumar, V, Abbas, A. K. and Aster, J. C. eds.), Elsevier, Philadelphia.

9. Martin-Vaquero, P., Moore, S. A., Wolk, K. E. and Oglesbee, M. J. 2011. Cerebral vascular hamartoma in a geriatric cat. J. Feline Med. Surg. 13: 286-290. [Medline] [CrossRef]

10. Padgett, S. L., Tillson, D. M., Henry, C. J. and Buss, M. S. 1997. Gingival vascular hamartoma with associated paraneoplastic hyperglycemia in a kitten. J. Am. Vet. Med. Assoc. 210: 914-915. [Medline]

11. Parkes, J. D., Kline, K. L., Riedesel, E. A. and Haynes, J. S. 2009. A vascular hamartoma arising from the cervical spine of a cat. J. Feline Med. Surg. 11: 724-727. [Medline] [CrossRef]

12. Schofield, D. and Cotran, R. S. 1999. Diseases of infancy and childhood. pp. 459-491. In: Pathologic Basis of Disease. 6th ed. (Cotran, R. S., Kumar, V. and Collins, T., eds.), WB Saunders Co., Philadelphia.

13. Smith, T. J., Baltzer, W. I., Ruaux, C. G., Heidel, J. R. and Carney, P. 2010. Gastric smooth muscle hamartoma in a cat. J. Feline Med. Surg. 12: 334-337. [Medline] [CrossRef]

14. Takagi, S., Mori, T., Watanabe, K., Kadosawa, T., Ochiai, K., Trigoe, S., Kitamura, J., Okumura, M. and Fujinaga, T. 2004. Mandibular squamous cell carcinoma with reactive bone proliferation in two cats. Nihon Jui Masui Gekagaku Zasshi 35: 89-94.

15. Taylor-Brown, F. E., Lamb, C. R., Martineau, H., Muir, C. and Beltran, E. 2018. Imaging diagnosis-imaging and histopathologic characteristics of a vertebral hamartoma in a cat. Vet. Radiol. Ultrasound 59: E12-E16. [Medline] [CrossRef]

16. Tjostheim, S. S., Kellihan, H. B., Csomos, R. A., McAnulty, J. and Steinberg, H. 2015. Vascular hamartoma in the right ventricle of a dog: Diagnosis and treatment. J. Vet. Cardiol. 17: 321-328. [Medline] [CrossRef]

17. Tsuka, T., Okamoto, Y., Yamamoto, N., Hayashi, K., Morita, T., Sunden, Y., Murahata, Y., Azuma, K., Osaki, T., Ito, N. and Imagawa, T. 2018. Unilateral rostral mandibulectomy for gingival vascular hamartoma in two calves. J. Vet. Sci. 19: 582-584. [Medline]

18. Veiga, I. B., Welle, M. and Agerholm, J. S. 2017. Congenital Cutaneous Panadnexal Papillomatous Hamartomas in a Calf. J. Comp. Pathol. 157: 183-187. [Medline] [CrossRef] 